\title{
Una mirada desde el análisis político del discurso a las conexiones entre campo político afrodescendiente, currículo y enseñanza de la historia en Uruguay
}

\author{
Doi: https://doi.org/10.25100/hye.v15i53.8656
}

Artículo recibido: 19-02-2018 Artículo aceptado: 10-09-2019

\section{Federico José Alvez Cavanna}

Profesor de historia egresado del Instituto de Profesores Artigas, Montevideo, Uruguay; Magister en Educación por la Universidad Estadual de Ponta Grossa, Paraná, Brasil y Doctor en Historia por la Universidad Federal do Paraná, Paraná, Brasil. Su énfasis investigativo se centra en la didáctica de la educación y la enseñanza históricas.

Universidade Estadual do Paraná, Brasil.

Correo electrónico: federico.alvez@unespar.edu.br

ORCID: 0000-0003-2980-9703

\section{Gustavo Diego Faget Caballero}

Profesor de Historia egresado del Instituto de Profesores Artigas, Montevideo, Uruguay, cuenta con un Diplomado en Sistema Internacional y Procesos de Integración Regional por la Facultad de Ciencias Sociales- Universidad de la República, Uruguay. Además de un Máster en Estudios Políticos Aplicados por la Fundación Internacional para Iberoamérica en Administración y Políticas Públicas, Madrid, España y un Magister en Políticas Públicas y Género por FLACSO, México. Es Profesor en Consejo de Educación Secundaria, Uruguay.

FLACSO-Uruguay.

Correo electrónico: gfaget@hotmail.com

ORCID: 0000-0003-3590-5363

Forma de citar este artículo: Alvez Cavanna, Federico José y Gustavo D. Faget Caballero. "Una mirada desde el análisis político del discurso a las conexiones entre campo político afrodescendiente, currículo y enseñanza de la historia en Uruguay". Historia y Espacio, vol. 15 nº 53 (2019): 43-66. Doi. org/10.25100/hye.v15i53.8656

Artículo Tipo 1: de investigación. 


\section{Una mirada desde el análisis político del discurso a las conexiones entre campo político afrodescendiente, currículo y enseñanza de la historia en Uruguay}

Resumen: La Ley de Acciones Afirmativas para Afrodescendientes promulgada en Uruguay el 21/8/2013 establece que los programas educativos y de formación docente deben incorporar los aportes de las comunidades afrodescendientes a la enseñanza de la historia y su participación en la construcción de la nación, así como sus diversas expresiones culturales. Pretendemos analizar los ecos y las irrupciones de este campo haciendo dialogar los aportes del análisis político del discurso, con el campo político afrodescendiente en América Latina y el Caribe y sus demandas desde la perspectiva poscolonial/decolonial para mostrar cómo aparecen algunas referencias a la historia de África y a los aportes de la cultura afrodescendiente en los marcos normativos y en los programas oficiales de Historia para educación media en Uruguay.

Palabras clave: Currículo, Enseñanza de la historia, Afrodescendencias.

\section{A look from the political analysis of the discourse of the connections between the Afrodescendant political field, curriculum and teaching of history in Uruguay}

Abstract: The Affirmative Action for Afrodescendants Act promulgated in Uruguay on 21th august, 2013, states that educational and teacher-training programs should incorporate the contributions of Afrodescendant communities in history teaching and present their participation in nation-building process so far, as well as theircultural expressions. We intend to analyze the echoes and the eruptions of this field by making a dialogue with the Political Analysis of Discourse contributions and the Afrodescendant political field in Latin America as well as Caribbean. The objective is to analyze their demands from the postcolonial perspective to show how some references to the History of Africa arise with the contributions of Afrodescendant culture in the norms and in the official programs of History for Basic Education in Uruguay.

Key words: Curriculum, History teaching, Afro-descendants. 


\section{Federico José Alvez Cavanna - Gustavo Diego Faget Caballero}

\section{Una mirada desde el análisis político del discurso a las conexiones entre campo político afrodescendiente, currículo y enseñanza de la historia en Uruguay}

\section{Introducción}

Buscamos con este trabajo poner en diálogo tres registros que permitan analizar y establecer conexiones entre el currículo escolar y la incorporación de las demandas del campo político afrodescendiente en la enseñanza de la Historia en el Uruguay. En primer lugar, utilizaremos los aportes del análisis político de discurso (APD) para la problematización de la noción de currículo, a través de las contribuciones teórico-conceptuales de Alicia de Alba ${ }^{1}$, Alice Casimiro López ${ }^{2}$ y Sebastián Plá3 ${ }^{3}$ En segundo término, esbozaremos cómo se constituye el campo político afrodescendiente en América Latina y el Caribe desde la perspectiva de Agustín Lao Montes ${ }^{4}$ y cuáles son sus demandas desde la posición del sujeto poscolonial abordado desde los enfoques poscoloniales/decoloniales. Finalmente, intentaremos ver cómo aparecen algunas referencias y representaciones de la historia de África y de los aportes de la cultura afrodescendiente en los marcos normativos y en los programas oficiales de Historia para la educación secundaria en Uruguay, teniendo en cuenta los debates, espacios e impactos abiertos por el propio campo político afrodescendiente.

1 Alicia de Alba, Currículum: crisis, mito y perspectiva (Madrid: Miño y Dávila editores, 1998).

2 Alice Casimiro Lopes, “Teorías pós-críticas, política e currículo", Educacao, Sociedade \& Culturas, n. ${ }^{\circ} 39$ (2013).

3 Sebastián Plá, "Evaluación de un profesor de Historia: un estudio de caso" (ponencia, XI Congreso Nacional de Investigación Educativa / 5. Educación y Conocimientos Disciplinares/), 2011.

4 Agustín Lao Montes, "Cartografías del campo político afrodescendiente en América Latina y el Caribe" en Más allá del decenio de los pueblos afrodescendientes, coords. Rosa Campoalegre Septien y Karina Bidaseca (coords.) (Buenos Aires: Clacso, 2017), 139-165. 
Una mirada desde el análisis político del discurso a las conexiones entre campo político afrodescendiente...

Federico José Alvez Cavanna - Gustavo Diego Faget Caballero

\section{Análisis político del discurso y currículo}

El texto fundante del horizonte teórico denominado análisis político del discurso (APD) es Hegemonía yestrategia socialista ${ }^{5}$ de Chantal Mouffe y Ernesto Laclau. Tomando como referencia su teoría del discurso, entendemos que toda representación debe asumirse como una realidad construida discursivamente en la cual las palabras y las acciones se articulan. Por eso, el currículo escolar se debe analizar como una práctica discursiva que se construye a partir de diversas interacciones en distintos ámbitos en que se desenvuelve: entre personas, objetos, relaciones sociales y de poder y prácticas culturales. Según Da Costa Pereira ${ }^{6}$, la finalidad del discurso en el ámbito del currículo es incorporar otros discursos producidos desde las políticas macrouniversalistas que atraviesan a las instituciones educativas oficiales y el diseño de sus políticas públicas; y los provenientes de las políticas microparticularistas que se materializan en las aulas, las salas de profesores, entre los alumnos, los equipos multidisciplinarios, las direcciones de los centros y el personal administrativo.

Laclau incorpora el concepto de significante vacío, entendido como palabras o imágenes con carácter de totalidad inconmensurable que intentan dominar el campo del discurso y cuyas principales características son: ambigüedad, polisemia, no fijación e inestabilidad. Este concepto es útil para problematizar algunos significados discursivamente considerados universales tales como libertad, democracia, justicia social, igualdad, reconocimiento, derechos, ciudadanía o espacio público.

Las luchas políticas en el sistema educativo se reflejan en el currículo y su análisis nos permite conocer la dimensión institucional y cultural de los proyectos educativos. Según Alicia de $\mathrm{Alba}^{8}$, el currículo se manifiesta a través de dos aspectos, el estructural-formal y el procesual-práctico, siendo este último el que se refiere a la vida escolar, otorgándole un carácter histórico a los procesos

5 Ernesto Laclau y Chantal Mouffe, Hegemonía y estrategia socialista (Buenos Aires: Fondo de Cultura Económica, 1985).

6 Maria Zuleide Da Costa Pereira, "A centralidade da pluralidade cultural nos debates contemporâneos no campo do currículo”, Currículo sem fronteiras IX, n.․․ 2, (2009).

7 Ernesto Laclau, La razón populista (Buenos Aires: Fondo de Cultura Económica, 2005).

8 De Alba, Curriculum, 1998. La autora distingue entre dimensiones generales y particulares; en la comprensión de las interacciones entre estas dos dimensiones estarían las claves para el análisis curricular. En cuanto a las dimensiones generales, la autora propone la dimensión social amplia, que contiene los aspectos culturales, políticos, económicos e institucionales; la dimensión institucional y la dimensión didáctico-áulica, como espacio de encuentro entre docentes y estudiantes, lugar donde lo educativo es posible, el encuentro cara a cara. 
educativos enmarcados en las luchas entre diversos proyectos políticossociales que tienen a los sistemas educativos como un escenario central. En este sentido, los discursos son correas de transmisión por donde circula la historia de las sociedades, la historia de la lengua, y nos permiten observar los cambios sociales y culturales, cuándo estos ingresan y se incorporan al plano de la discursividad ${ }^{9}$.

En el discurso entre profesores/as y alumnos/as se representa el hilo que une sociedad, lenguaje y cultura y el currículo se presenta como un sistema de redes de significados permeadas por relaciones de poder y en constante desplazamiento en tanto proceso cultural de pertenencia a diversos grupos sociales. Es también una oportunidad para producir cambios en los procesos de reconocimiento y legitimidad del poder de grupos sociales subalternizados (étnico-raciales, identidades de género, subculturas juveniles, feminismos, etc.)

Por currículum se entiende a la síntesis de elementos culturales (conocimientos, valores, costumbres, creencias, hábitos) que conforman una propuesta político-educativa pensada e impulsada por diversos grupos y sectores sociales cuyos intereses son diversos y contradictorios, aunque algunos tiendan a ser dominantes o hegemónicos, y otros tiendan a oponerse y resistirse a tal dominación o hegemonía. Síntesis a la cual se arriba a través de diversos mecanismos de negociación e imposición social ${ }^{10}$.

El currículo no es un espacio educativo neutro y aislado; refleja intereses políticos; en el contexto de la práctica se pueden dar alteraciones supeditadas a la experiencia y subjetividad del educador y al contexto histórico-social, que permiten la articulación de discursos/otros. No hay discurso encerrado en sí mismo; siempre se construye como respuesta a otros discursos y desata un juego entre confrontación y encuentro, entre discurso ajeno y propio, en el cual el currículo y sus contenidos pueden ser entendidos como campos sujetos a luchas e interpretaciones en los que diversos grupos sociales disputan sentidos y representaciones.

Este carácter de síntesis nos permite comprender por qué es difícil concebir al currículum como un sistema congruente y articulado, al tiempo que visualizarlo como una totalidad en cuya articulación se presentan las

\footnotetext{
9 Mijail Bajtin, Estética de la creación verbal (México: Siglo XXI, 1995).

${ }^{10}$ De Alba, Curriculum, 1998, 59
} 
Una mirada desde el análisis político del discurso a las conexiones entre campo político afrodescendiente...

Federico José Alvez Cavanna - Gustavo Diego Faget Caballero

contradicciones, el juego de negociaciones e imposiciones. La síntesis implica el carácter de lucha

[...] si bien en un currículum se incorporan los elementos culturales que se han considerado valiosos, esta consideración es la que sostienen los grupos dominantes de una sociedad; sin embargo, en un currículum se expresan, aunque ocupando diferentes espacios en los planos estructuralformal y procesal-práctico, los elementos culturales pertenecientes a otros grupos socioculturales que logran incorporarse en dichas síntesis $[\ldots]^{11}$

Desde esta perspectiva, y al incorporarse la categoría de significante vacío, el currículo, en su universalidad, amplía su significado incorporando un espacio abierto para grupos sociales invisibilizados. En este sentido, entendemos al currículo atravesado por discursos producidos en marcos sociales en los cuales, de manera contingente, se dan fijaciones y desplazamientos de modelos curriculares centrados en grandes temas generales como: derechos humanos, diversidad cultural, libertades, interdisciplinariedad, multidisciplinariedad, ética, multiculturalismo, interculturalismo, género. De esta forma, los discursos provenientes del contexto social son capturados por las agencias políticas que normatizan los textos (políticas educativas, reglamentos, planes y programas, leyes, circulares, directrices curriculares) para las acciones de los diversos grupos sociales en tensión ${ }^{12}$.

En este sentido, Alice Casimiro Lopes entiende que los textos de las políticas curriculares solo pueden ser entendidos como políticos, si se los observa en el marco de una operación hegemónica, formando parte de un discurso que intenta fijar de manera provisoria ciertos significados. De esta manera, entiende la autora, que los significantes vacíos se asocian a la multiplicidad de significantes flotantes, aquellos cuyos sentidos y significados se desplazan de forma constante, siendo precisamente este componente lo que permite la fluctuación necesaria para la incorporación de nuevas demandas.

\section{La emergencia del campo político afrodescendiente y sus luchas por el currículo}

Llegado este punto, cabe preguntarse cómo se manifiestan las demandas provenientes del campo político afrodescendiente en las luchas por el currículo.

\footnotetext{
${ }^{11}$ De Alba, Curriculum, 1998, 60

${ }^{12}$ Da Costa, "A centralidade da pluralidade”...
} 
Y, también, cómo se identifican en el currículo y en la enseñanza de la Historia las luchas por la constitución de las representaciones afro.

La irrupción de los denominados nuevos movimientos sociales a partir de los años 70-80 (feministas, ecologistas, pueblos originarios, juventudes, afrodescendientes) y sus reivindicaciones ha producido impactos en los currículos; tal es el caso de los movimientos afrodescendientes en América Latina y el Caribe. Anclados en las teorías poscoloniales, decoloniales y en el paradigma de las intersecciones raza-etnia-sexo-género-clase, estos movimientos iniciaron una fuerte crítica a las diversas formas de opresión que restringen las posibilidades e invisibilizan a diversos colectivos y se constituyeron en lo que Agustín Lao Montes ${ }^{13}$ denomina un campo político. La acumulación de experiencias y luchas locales e internacionales por la descolonización del saber/poder/ser implicó el aterrizaje de los movimientos afrodescendientes en la arena de lucha curricular, buscando visibilizar sus saberes, sus historias, y sus identidades.

Según Lao Montes el campo político afrodescendiente comienza a constituirse sobre la base de cinco factores que conducen a la articulación de los movimientos afrodescendientes en América Latina durante la década del 80; estos factores se yuxtaponen y remiten a un recorrido genealógico que se remonta al pensamiento y acción anticolonial. En primer lugar, reconoce la emergencia de los movimientos de liberación nacional en África y el Caribe, que alimentaron la toma de conciencia y apuntalaron la construcción de las identidades afro. Estos movimientos se conectan con reivindicaciones anticapitalistas y antisistémicas que tienen sus raíces en las décadas de los 60 y 70. En segundo lugar, nuevas luchas, y la redefinición de viejas luchas, frente al impacto de las oleadas de ajuste neoliberal acontecidas a partir del Consenso de Washington (1989). En tercer lugar, las luchas de los movimientos afro se conjugan conla emergencia de otros movimientos sociales que amplían las luchas por el reconocimiento y la ciudadanía, dando comienzo al establecimiento de lo que hoy denominamos la nueva agenda de derechos (ecologistas, diversidad sexual, pueblos originarios, jóvenes). Esta constelación de movimientos tuvo un impacto político importante en la incorporación del enfoque de DD. HH. en las agendas públicas y gubernamentales que terminaron concretándose en el diseño e implementación de políticas públicas de reconocimiento y en acciones afirmativas. Un cuarto punto se refiere a la organización de redes translocales $\mathrm{y}$ transnacionales que desembocaron en las articulaciones de demandas que el

${ }^{13}$ Lao Montes, “Cartografías”, 139-165. 
movimiento afrolatinoamericano y el afrocaribeño llevaron a la Conferencia de Durban (Sudáfrica) contra el racismo y la discriminación en 2001. En último término, se produce un giro de la militancia afro desde los partidos políticos de izquierda y socialdemócratas hacia organización autónoma en el contexto de la crisis del socialismo real. Todo esto desembocó en el diseño de una agenda política afro que, en una lógica de abajo-arriba, buscó, como mencionamos, impactar en las agendas gubernamentales.

As ideias de centro e margens, de superioridade cultural, disciplinaridade e nação, o eurocentrismo e os registros orientais no ocidente são questionados, de forma associada às discussões sobre gênero, raça, classe, sexualidade e linguagem. Tais questões são discutidas em termos de império e imperialismo, cultura popular e diáspora, identidade/ identificação, representação e multiculturalismo $[\ldots]^{14}$.

Alice Casimiro Lopes habla de un tiempo de explosión de demandas y de luchas por el reconocimiento y las diferencias, en el cual el registro de los estudios poscoloniales permite que alumnos y profesores discutan las jerarquías y las relaciones de opresión, rompiendo con los sistemas eurocéntricos y colonialistas. Estas discusiones, al manifestarse en el plano procesual-práctico del currículo, se relacionan con lo que Sebastián Plá ${ }^{15}$ denomina discurso histórico escolar, es decir, en la transposición didáctica.

La teoría poscolonial, como dislocación epistémica, busca desplegarse en el diseño y desarrollo del currículo. Pero ahora, ¿qué es la crítica poscolonial?, se pregunta el teórico Robert Young ${ }^{16}$; la crítica poscolonial trata de deshacer la herencia ideológica del colonialismo en el mundo descolonizado y en el mundo occidental, es decir, deconstruir Occidente. Es una crítica al eurocentrismo y al etnocentrismo, una crítica a la norma impuesta por el punto de vista del hombre/heterosexual/blanco/occidental. En el campo de la historiografía, los estudios poscoloniales buscan cuestionar y desarmar la historia historicista como una totalidad única. Young sostiene que los referentes principales de los estudios poscoloniales son los críticos: Edward Said, Gayatri Spivak y Homi Bhabha; sus teorías y conceptos se vinculan con la tradición anticolonial de

${ }^{14}$ Alice Casimiro Lopes, “Teorías pós-críticas, política e currículo”, Educacão, Sociedade \& Culturas, n. ${ }^{\circ} 39$ (2013): 15.

${ }^{15}$ Plá, “Evaluación de un profesor”, 2011.

${ }^{16}$ Robert Young, ¿¿Qué es la crítica poscolonial?” (2016), http//robertjyoung.com/crítica poscolonial.pdf 
Léopold Sédar Senghor, Aimé Césaire y Franz Fanon y con la teoría crítica francesa, principalmente con el posestructuralismo de Jacques Derrida, a través del concepto de deconstrucción aplicado a la descolonización cultural, lo que tiene como resultado un lenguaje teórico híbrido producto de la interacción cultural. Como sostiene Sidi Mohamed Omar ${ }^{17}$, la hibridez como principio cultural resulta una categoría crítica para pensar y construir formas creativas de interacción y transformación cultural hacia prácticas pacíficas de convivencia.

Edward Said aportó la noción de orientalismo, entendida como la invención de Oriente por Occidente, una representación distorsionada y caricaturizada en la que Oriente refiere a lo exótico, los excesos, lo despótico. Gayatri Spivak, desde el Grupo de Estudios Subalternos, escuela historiográfica desarrollada en la India, mostró la doble invisibilización de las mujeres en su país; una, provocada por el imperialismo británico; la otra, generada por el patriarcado en la sociedad autóctona. Homi Bhabha desarrolló dos importantes conceptos: la ambivalencia, entendida como la atracción y repulsión simultáneas entre colonizado y colonizador, y la hibridez que marca todo proceso cultural desde su matriz inicial.

En el caso de América Latina, es fundamental el aporte teórico de Aníbal Quijano con su interpretación de la modernidad desde la experiencia histórica latinoamericana, acuñando la categoría colonialidad, fundamentalmente la colonialidad del poder. Esta matriz de dominación, creada por los agentes y dispositivos del expansionismo europeo a partir del siglo XVI, descansa sobre una trama de dominación mundial, el sistema mundo/moderno/capitalista/ eurocéntrico. A partir de esta imposición, el relato de la historia europea se confunde con el relato de la historia universal. Es recién a partir de 1492 que Europa se posiciona en el centro; antes, Europa era sólo otro espacio marginal ${ }^{18}$ ubicado en los márgenes de Asia y el Mediterráneo oriental. Los europeos inventaron América, así como inventaron Oriente como lo demostró Edward Said (1978). Estas invenciones y avasallamientos se apoyan en la colonialidad del poder, categoría que se forma a partir del primer capitalismo en su forma mercantil, en el eurocentrismo como tecnología del saber/poder y en una supuesta moralidad y etnicidad superiores de los europeos con respecto a otros pueblos. Este patrón de poder colonial global se apoya en cuatro pilares: la empresa capitalista, la familia burguesa, los estados nacionales y

${ }^{17}$ Sidi Mohamed Omar, Los estudios poscoloniales: una introducción crítica (Castellón: Publicaciones de la Universidad Jaume I, 2007).

${ }^{18}$ Enrique Dussel, Europa, modernidad y eurocentrismo (Buenos Aires: Clacso, 2000). 
Una mirada desde el análisis político del discurso a las conexiones entre campo político afrodescendiente...

Federico José Alvez Cavanna - Gustavo Diego Faget Caballero

el eurocentrismo, que se imponen a través de dos procesos históricos: a) La racialización de los seres humanos, en la se establecen jerarquías entre humanos (varones/blancos/europeos/heterosexuales) y no humanos (africanos/as, pueblos originarios de América, asiáticos/as) y b) articulación con formas de control del trabajo.

De esta manera, la idea de raza legitima las relaciones de dominación impuestas por la conquista; de acuerdo con Quijano, sería el instrumento más eficaz y perdurable de dominación universal. Las identidades negro/indio surgen con la colonialidad del poder y se reproducen a través de la lógica explotación/ dominación institucionalizada, como mencionamos, mediante el Estado, los modelos familiares y todas las formas de socialización. Según Quijano ${ }^{19}$, las formas de existencia social que se reproducen en el largo plazo se articulan en cinco espacios de existencia: trabajo, sexo, subjetividad/intersubjetividad, autoridad y naturaleza. En estos espacios se reproduce el poder apoyado en tres elementos, también articulados: dominación, explotación y conflicto; el primero como la posibilidad del segundo y este provocando necesariamente el tercero.

Las pensadoras feministas Rita Segato ${ }^{20}$ y María Lugones ${ }^{21}$ incorporan al análisis crítico la noción de colonialidad de género desde una perspectiva decolonial. Así como, de acuerdo con los esquemas de dominación europeo, el indio y el negro no son humanos y no tienen control de su sexualidad, las mujeres esclavizadas padecen el prejuicio de la no-razón, lo que las convierte también en no-humanas, acentuando su invisibilización en el devenir de los procesos histórico-sociales. En el interesante libro compilado por Zulma Palermo Para una pedagogía decolonial ${ }^{22}$, la compiladora y Pablo Quintero

${ }^{19}$ Aníbal Quijano, “Colonialidad del poder, eurocentrismo y América Latina” en La colonialidad del saber:eurocentrismo y ciencias sociales. Perspectivas latinoamericanas, comp. Edgardo Lander (Buenos Aires: Clacso, 2000).

${ }^{20}$ Rita Segato, "El Edipo brasilero: la doble negación de género y raza”, en Perfiles del feminismo iberoamericano, vol. 3, comp. María Luisa Femenías (Buenos Aires: Catálogos, 2007), 190221. Rita Segato, "La norma y el sexo: frente estatal, patriarcado, desposesión, colonialidad", en Genealogías críticas de la colonialidad en América Latina, África, Oriente, coord. Karina Bidaseca (Buenos Aires: Clacso, 2016).

${ }^{21}$ María Lugones, "Colonialidad y género", Tabula Rasa (Universidad Colegio Mayor de Cundinamarca, Bogotá) 9 (julio-diciembre 2008):73-101. María Lugones, "Hacia un feminismo descolonial”, La manzana de la discordia 6, 2 (julio - diciembre 2011): 105-119.

${ }^{22}$ Zulma Palermo, comp., Para una pedagogía decolonial (Buenos Aires: Ediciones del Signo, 2017). 
realizan un contrapunto en el análisis del pensamiento de Aníbal Quijano con respecto a los problemas en torno a la colonialidad de género. Palermo apunta:

[...] María Lugones amplía el sentido de la matriz colonial de poder propuesta por Quijano, por entender que esta (...) sigue adherida a una idea masculinocéntrica de género y la sexualidad, en su concepción, por el contrario, lo que existe en las sociedades subalternizadas es un entramado que impide la separación de sus componentes; así género, raza, sexualidad y trabajo resultan inseparables en la vida cotidiana ${ }^{23}$.

Catherine Walsh ${ }^{24}$ sostiene que la colonialidad como matriz ha impuesto un colonialismo interno que entra en la psique y que hay que reconocerse para descolonizarse, haciendo un camino sinuoso y plagado de intersticios. Su programa propone romper con las pedagogías tradicionales; en primer lugar, reconociendo que la pedagogía no se limita solo a las instituciones educativas; destaca el papel que desempeñan los movimientos sociales como portadores y constructores de pedagogías. Walsh afirma que la pedagogía de Frantz Fanon ${ }^{25}$ busca una nueva humanidad cuestionadora. Ahora, ¿se puede promover una pedagogía poscolonial desde la educación formal? La posición de Walsh se inclina por la educación popular. Aquí parece abrirse un debate entre la autonomía y la institucionalización, como ocurrió en el feminismo en los 60-70. Inés Fernández Mouján ofrece otras posibilidades y las anuda por un instante cuando le preguntan sobre ¿cuál debería ser el escenario de la pedagogía poscolonial, la educación formal o la educación popular?:

Entiendo que se hace necesario discutir los alcances y las prácticas de una educación descolonial en todos los ámbitos que estemos dispuestos a poner en cuestión: la dominación colonial, la línea de color, lo dado, lo innato, en definitiva, la colonialidad del poder... por donde queramos entrar. No me parece que un escenario sea mejor que el otro. Hoy en día hay una ventaja: la educación formal ha caído bajo sospecha en su propio

${ }^{23}$ Zulma Palermo, Para una pedagogía decolonial (2017), 32

${ }^{24}$ Catherine Walsh, "Fanon y la pedagogía decolonial", Revista NuevAmérica, n. ${ }^{\circ} 122$ (Rio de Janeiro, junio 2009): 60-63. Ver también Catherine Walsh "Interculturalidad, plurinacionalidad y decolonialidad: las insurgencias político-epistémicas de refundar el Estado”, Tabula Rasa, 9 (Bogotá, julio-diciembre 2008): 131-152 y Catherine Walsh, "Interculturalidad, conocimientos y decolonialidad", Signo y Pensamiento XXIV, n. ${ }^{\circ} 46$ (Cali, enero-junio 2005): $39-50$.

${ }^{25}$ Frantz Fanon, Por la revolución africana (México: FCE, 1964). 
Una mirada desde el análisis político del discurso a las conexiones entre campo político afrodescendiente...

Federico José Alvez Cavanna - Gustavo Diego Faget Caballero

seno, entonces allí hay maestrxs, profesores y estudiantes que la ponen en jaque cotidianamente. Diría que por fuera de la escuela hay mayor predisposición, pues en las experiencias de educación popular hay una intención manifiesta de llevar adelante prácticas críticas, si se quiere liberadoras o descolonizadoras. No digo que esto se cumpla a pie juntillas... pero hay una intención y unas prácticas que se plantean recuperar historias y legados críticos anticoloniales. Estrategias y metodología de lucha, rebeldía y organización para resistir la dominación y buscar nuevas formas de educación $[\ldots]^{26}$.

Estas declaraciones nos permiten reflexionar sobre los intersticios que se abren en la educación formal para la tematización de las preceptivas poscoloniales/decoloniales. Si bien en América Latina la conformación del Estado y de los sistemas estatales de educación a fines del siglo XIX se hizo sobre la base de una homogenización cultural, que podríamos denominar colonialismo/interno/elitista, en las contradicciones de los espacios y ausencias en que se dejó a los grupos subalternizados (pueblos originarios y colectivos afro, entre otros) se pueden encontrar oportunidades para la visibilización del sujeto colonial a partir de la emergencia de coaliciones promotoras del enfoque poscolonial/decolonial.

\section{Ecos e irrupciones del campo político afrodescendiente en el currículo y en la enseñanza de la Historia en Uruguay}

Podemos afirmar que, en los últimos treinta años, el movimiento afrouruguayo ha irrumpido con fuerza tanto en las agendas públicas como en las gubernamentales. Este impulso está asociado con el fin de la dictadura cívico-militar (1973-1985), con la incorporación de la perspectiva de DD. HH. en las políticas públicas, con el rotundo fracaso de las políticas neoliberales en América Latina y, más recientemente, con la llegada al gobierno de la coalición de izquierda Frente Amplio. Pero es sobre todo a partir de la Conferencia de Durban (2001) contra el racismo y la discriminación racial que el Estado uruguayo empieza a hacerse eco de las reivindicaciones y demandas de los colectivos afro. A partir de ese momento, junto a las tradicionales ${ }^{27}$ organizaciones afrouruguayas, emergen

${ }^{26}$ Marta Yedaide, "Fanon, Freire y las posibilidades concretas de una pedagogía descolonial: entrevista a Inés Fernández Mouján”, Revista Entramados (Mar del Plata, 2014): 37, http:// fh.mdp.edu.ar/revistas/index.php/entramados

${ }^{27}$ Asociación Cultural y Social Uruguay Negro (fundada en 1941) y Organizaciones Mundo Afro (fundada en 1988). 
nuevos movimientos sociales afro ${ }^{28}$ que dialogan entre la militancia autónoma y la profesionalidad institucionalizada, y se establece una suerte de diálogo/ confrontación entre académicos/as y militantes. Estos debates e impactos se hacen sentir en la producción académica ${ }^{29}$, en la elaboración de proyectos de investigación, monografías de grado y posgrado ${ }^{30}$, en ofertas educativas de posgrado $^{31}$, en la elaboración de informes, diagnósticos y propuestas sobre

${ }^{28}$ Desde hace algunos años han surgido algunas organizaciones de mujeres afrouruguayas, como Mizangas o Afrogama, que incorporan entre sus principios y prácticas el enfoque de la interseccionalidad etnia/raza/género/sexualidad/clase, también, pero con un enfoque desde la militancia artístico-cultural está Triangulación Kultural con proyección e intercambios a nivel latinoamericano/caribeño, africano y con la diáspora en Europa.

${ }^{29}$ En el año 2000, el Centro de Estudios Interdisciplinarios Uruguayos (FHCE, Udelar) organizó el Seminario Grupos Minoritarios en el Uruguay. En el año 2003, por iniciativa de los investigadores Arturo Bentancur, Ana Frega y Alex Borucki, se organizó el Seminario Estudios sobre la Cultura Afrorioplatense. Historia y Presente. Además de destacados académicos, participaron militantes del movimiento afro-uruguayo. Más recientemente, en 2016 y 2017, se celebraron las dos primeras jornadas académicas sobre afrodescendencias impulsadas por las oficinas especializadas del Ministerio de Desarrollo Social; estos eventos reunieron a diversos académicos y académicas, así como a militantes, y como resultado se publicaron dos libros. También recomendamos los trabajos de Alex Borucki, Natalia Stalla y Karla Chagas, quienes investigan la temática desde la Facultad de Humanidades y Ciencias de la Educación; es muy interesante su trabajo "Debates y problemas sobre los estudios recientes entorno a la esclavitud en el río de la Plata (1750-1850)”. Ver también Roberto Bracco, José Lopez Mazz, Beatriz Orrego Rojas, Nicolás Batalla y Rodrigo Bongiovanni, Esclavitud y afrodescendientes en Uruguay: una mirada desde la antropología (Montevideo: Facultad de Humanidades y Ciencias de la Educación, Universidad de la República, Proyecto: "Arqueología y esclavitud. Construyendo patrimonio, "lugares de memoria", con escolares, desde la escuela y a través de la investigación, 2011).

${ }^{30}$ Algunos ejemplos son: Germán Asencio Sánchez, "Proyecto de investigación de dispositivos rituales afrouruguayos y su eficacia terapéutica: la danza de los muertos pobres" (Montevideo: Facultad de Psicología-Udelar, 2015). Juan Carlos Cristiano, "Raíces africanas en Uruguay: un estudio sobre la identidad afrouruguaya” (Monografía final de grado, Licenciatura en Sociología, Facultad de Ciencias Sociales, -Udelar, 2008). Mónica Olaza, "La cultura afrouruguaya una expresión del multiculturalismo emergente de la relación global-local" (Tesis de Maestría en Sociología, Facultad de Ciencias Sociales, Udelar, 2008). Lil Natalia Vera, "Discriminación racial e identidad: la experiencia de las generaciones recientes de afrodescendientes en Uruguay” (Monografía final de grado, Licenciatura en Sociología, Facultad de Ciencias Sociales, -Udelar, 2011).

${ }^{31}$ Diploma de posgrado en Afrodescendencias y Políticas Públicas, Facultad de Ciencias Sociales, Udelar. 
Una mirada desde el análisis político del discurso a las conexiones entre campo político afrodescendiente...

Federico José Alvez Cavanna - Gustavo Diego Faget Caballero

políticas públicas con carácter internacional, regional y local ${ }^{32}$, en la creación de institucionalidades oficiales ${ }^{33}$, en la ocupación de cargos jerárquicos dentro de oficinas estatales ${ }^{34} \mathrm{y}$, en el caso específico de la educación, a través de programas transversales y guías didácticas ${ }^{35}$. Sin embargo, toda esta acumulación no se refleja en los programas de Historia que rigen actualmente la enseñanza secundaria en Uruguay. En este sentido, es interesante la reflexión crítica que hace Borucki:

[...] el nuevo movimiento negro uruguayo ha sido el mayor actor en la revitalización del discurso del "aporte africano" a la formación nacional. Las Organizaciones Mundo Afro surgieron en la escena uruguaya en 1988 como resultado de las nuevas demandas del movimiento negro uruguayo y de la apertura democrática. Además de denunciar en forma eficaz el racismo, esta ONG se propuso revertir la "invisibilidad histórica de los afrodescendientes" [...] También se propuso romper "con el discurso oficial e histórico" sobre la población negra, estableciendo el rescate de "episodios históricos" desde la perspectiva "de los descendientes". De este modo, la organización urgía la revisión de la historia sobre la presencia africana en Uruguay y su uso político. La exaltación del “aporte africano” a la nación,

${ }^{32}$ Ver: Ministerio de Educación y Cultura, "Hacia un plan nacional contra el racismo y la discriminación. Informe final” (Montevideo: Ministerio de Educación y Cultura-MEC, 2011). Ver: Lucía Sucro Somma, Población afrodescendiente y desigualdades étnico-raciales en Uruguay (Montevideo: PNUD, 2008).

${ }^{33}$ Algunos ejemplos son: Área de Coordinación y Promoción de Políticas Públicas de Acción Afirmativa para Afrodescendientes, Dirección de DD. HH. del Ministerio de Educación y Cultura; Departamento de Mujeres Afrodescendientes, Instituto Nacional de las Mujeres, Ministerio de Desarrollo Social.

${ }^{34}$ En la actualidad la Lic. Ana Karina Moreira dirige el Departamento de Mujeres Afrodescendientes en el marco de Inmujeres-Mides, cargo anteriormente ocupado por la Dra. Alicia Esquivel. Inmujeres fue presidida por Beatriz Ramírez. Romero, Jorge Rodríguez fue designado durante el primer gobierno del Dr. Tabaré Vázquez como embajador itinerante para los pueblos afrodescendientes en el marco del Ministerio de Relaciones Exteriores. El Lic. Juan Pedro Machado ocupó la dirección de la oficina del Área de Coordinación y Promoción de Políticas Públicas de Acción Afirmativa para Afrodescendientes. Dirección de DD. HH. del Ministerio de Educación y Cultura

${ }^{35}$ Ver: Valentina Brena y Gonzalo Brown, Guía didáctica: educación y afrodescendencias (Montevideo: Mides-Inmujeres-Anep, 2016). El Consejo de Formación en Educación, marco institucional en el cual se forman los educadores/as uruguayos en todos los niveles (primera infancia, educación primera, secundaria y técnica profesional), está intentando transversalizar el enfoque de DD. HH. a través del Departamento de DD. HH. y Género del CFE, en el cual se incorpora la temática afrodescendiente. 
realizada con el estilo de la historiografía de principios de siglo XX, pero con las urgencias políticas de fin de siglo, se abría paso hacia la década de $1990[\ldots]^{36}$

Estas tramas, conformadas por espacios y debates, no son ajenas a los docentes de Historia, lo que significa que, en los programas oficiales de estudio para enseñanza secundaria, las representaciones afro se presentan distorsionadas/folclorizadas. Sin embargo, a pesar de que el Estado uruguayo ha asumido el compromiso de incorporar esta perspectiva, esto aún no se concreta plenamente y la invisibilidad permanece porque no son muchos los docentes que trabajan esta temática en el aula.

Uno de los debates más interesantes es el planteado por Borucki, en relación con el diálogo / confrontación entre historiadores profesionales e historiadores militantes. En este sentido apunta:

[la] producción historiográfica de Montaño se halla más vinculada a las demandas de las organizaciones no gubernamentales que a los objetivos de la historiografía académica. Las salvedades sobre esta clasificación conducen al tema que ilustra la conclusión de este artículo: el despliegue de un tablero de competencia/colaboración entre el medio universitario local y los grupos de afrodescendientes en su relación con el poder político y los organismos internacionales. ${ }^{37}$

Mientras tanto, Osar Montaño define la perspectiva de su trabajo de esta forma:

[...] Yo soy historiador, pero antes que ello soy militante contra el racismo; mi vida gira en torno a todo esto, no lo hago como profesional solamente. Mi contribución pasa por lo que pueda aportar en lo histórico, revelando una historia que no es conocida, hacer charlas en las escuelas y en los liceos para que los chiquilines no tengan vergüenza de decir que son negros o indios. Yo perdí mi apellido indio, que era Subitú, porque mi tatarabuelo no reconoció a mi bisabuelo, sin embargo, el apellido se mantuvo gracias a la

\footnotetext{
${ }^{36}$ Alex Borucki, "Entre el aporte a la identidad nacional y la reivindicación de las minorías. Apuntes sobre los afrodescendientes y la esclavitud en la historiografía uruguaya", Revista História (São Leopoldo, Unisinos) 10, n.ํㅜ (2006): 317.

${ }^{37}$ Borucki, "Entre el aporte”, 311.
} 
tradición oral que mi bisabuelo transmitió a mi abuela, que no se reconocía como indígena $[\ldots]^{38}$

En el caso de Uruguay, las irrupciones del campo político afrodescendiente y sus luchas por el reconocimiento se reflejan en el marco normativo local y en las disposiciones jurídicas internacionales. Estos impactos no se producen por la concesión de los organismos internacionales, sino que son el reflejo de las articulaciones del movimiento afro a nivel translocal y transnacional. El artículo n. ${ }^{\circ} 13$ de la actual Ley General de Educación n. ${ }^{\circ} 18437$ en Uruguay, cuando establece los fines del sistema educativo, propende:

al desarrollo de la identidad nacional desde una perspectiva democrática, sobre la base del reconocimiento de la diversidad de aportes que han contribuido a su desarrollo, a partir de la presencia indígena y criolla, la inmigración europea y afrodescendiente, así como la pluralidad de expresiones culturales que enriquecen su permanente evolución.

Promover la búsqueda de soluciones alternativas en la resolución de conflictos y una cultura de paz y de tolerancia, entendida como el respeto a los demás y la no discriminación ${ }^{39}$.

La construcción de la identidad nacional por las elites latinoamericanas se basó en el mito de pertenecer a una comunidad imaginada con pedagogías nacionales etnocéntricas. Fueron construidos sistemas educativos nacionales creando programas y currículos con base en lo que Frantz Fanon denomina "zona del no ser" para las representaciones sobre las africanías. Según Mario Rufer $^{40}$, el Estado Nación (colonial) se legitima a partir de que logra representar/ hablar por la nación. En este sentido discurren las palabras de Romero Rodríguez, uno de los principales intelectuales y activistas afrouruguayos:

[...] cómo hacer para que la academia uruguaya entienda que hubo 40 años de exclusión y hubo solo dos proyectos de reconocimiento de nuestra

\footnotetext{
${ }^{38}$ Juan Carlos Cristiano, "Raíces africanas en Uruguay: un estudio sobre la identidad afro-uruguaya” (Monografía final de grado, Licenciatura en Sociología, Facultad de Ciencias Sociales, Udelar, 2008), 50, Anexo entrevista a Óscar Montaño.

${ }^{39}$ Ley General de Educación n. ${ }^{\circ} 18437$.

${ }^{40}$ Mario Rufer, "Nación y condición poscolonial. Sobre memoria y exclusión en los usos del pasado", en Genealogías críticas de la colonialidad en América Latina, África y Oriente, coord. Karina Bidaseca (Buenos Aires: Clacso-Idaes, 2016).
} 
gente en la Universidad de la República, uno en 1954 que yo le mencionaba y otro cuando vino usted a invitarnos a la FHCE. ¿Qué pasó en esos 40 años? Resistimos como cultura, como pueblo, como desarrollo. O sea, el problema no es para enseñar a los negros. ¿Qué visión selleva ese muchacho blanco? Recrea de esta forma las culturas hegemónicas, esa visión..., y deja a partes de la humanidad afuera. Me parece que eso es multiplicador..., para que el racismo se multiplique. Entonces..., ¿cómo la academia se abre a una nueva interpretación del mundo y de las civilizaciones...?, nosotros lo hablábamos el otro día con el profesor de historia, es incomprensible que nuestros gurises ${ }^{41}$ que son parte de los 180.000 negros uruguayos y la tercera población o comunidad étnica del país, aproximadamente 60.000 gurises de varias edades, cómo esos gurises tienen que conocer sobre el imperio bantú, la civilización malawi... Lo aprenden acá, las 7, 8 civilizaciones del África, de dónde venimos, tenemos que romper ese esquema que venimos de los barcos, no venimos de los barcos ${ }^{42}$.

En cuanto a la normativa internacional, la declaración y plan de acción de Durban (2001):

Insta a los Estados a que hagan lo necesario para que en los programas de estudios se incluya la enseñanza cabal y exacta de la historia y la contribución de los africanos y los afrodescendientes [...]:

Insta a las Naciones Unidas, a otras organizaciones internacionales y regionales competentes y a los Estados a que contrarresten la minimización de la contribución de África a la historia y la civilización mundiales, desarrollando y aplicando a tal efecto un programa específico y amplio de investigación, educación y comunicación social a fin de difundir ampliamente una visión equilibrada y objetiva de la fundamental y valiosa contribución de África a la humanidad $[. . .]^{43}$.

En septiembre del 2013 se promulgó en Uruguay la Ley n. 19122 "Afrodescendientes: normas para favorecer su participación en las áreas

${ }^{41}$ Denominación coloquial para referirse a niños/as y adolescentes en Uruguay.

${ }^{42}$ Sonia Romero Gorski, “Entrevista a Romero J. Rodríguez”, Revista de Antropología, (Montevideo, FHCE), (2001):154. En aquel momento Romero J. Rodríguez era el presidente de Asociaciones Mundo Afro y coordinador general de las organizaciones afro de América Latina y el Caribe.

${ }^{43}$ Conferencia Mundial contra el Racismo, la Discriminación Racial, la Xenofobia y las formas conexas de Intolerancia. Edición del 31 de agosto al 8 de setiembre de 2001, Durban, Sudáfrica. 
Una mirada desde el análisis político del discurso a las conexiones entre campo político afrodescendiente... Federico José Alvez Cavanna - Gustavo Diego Faget Caballero

educativa y laboral”. Dicha norma establece “[...] incorporar los aportes de las personas afro a la construcción nacional como parte de las currículas en todos los niveles educativos" ${ }^{” 4}$. En su artículo n. ${ }^{0} 8$ especifica:

Seconsidera de interésgeneral que los programas educativos y de formación docente incorporen el legado de las comunidades afrodescendientes en la historia, su participación y aportes en la conformación de la nación, en sus diversas expresiones culturales (arte, filosofía, religión, saberes, costumbres, tradiciones y valores) así como también sobre su pasado de esclavitud, trata y estigmatización, promoviendo la investigación nacional respectiva ${ }^{45}$.

Analizando los programas de Historia para educación secundaria que rigen en la actualidad, sólo el programa de $2 .{ }^{\circ}$ año para ciclo básico ${ }^{46}$ establece, entre sus contenidos, trabajar la esclavitud y los orígenes de los esclavos africanos en el ítem: Los africanos. Los lugares de origen; las culturas africanas. El tráfico de esclavos. No obstante, en la bibliografía sugerida, de los 111 libros recomendados, hay solo una excepción en la que se recomienda el estudio regional compilado por Bentancur, Borucki y Frega, titulado Estudios sobre la cultura afrorioplatense. Historia y presente ${ }^{47}$. El programa también hace recomendaciones filmográficas y de los 48 títulos solamente cinco se refieren a afrodescendencias ${ }^{48}$. Entre los conceptos a trabajar, el programa sugiere la exploración de la hibridez cultural, tópico privilegiado para desarrollar a su vez los conceptos de diáspora, africanías y transanacionalidad ${ }^{49}$.

${ }^{44}$ Ministerio de Desarrollo Social, "1.er Informe de avances Ley n. ${ }^{\circ} 19122$ Afrodescendientes. Normas para favorecer su participación en las áreas educativa y laboral” (Montevideo: 15 de julio de 2015): 4, https://issuu.com/marceloe.ortizuriarte/docs/primer-informe-de-avances-por-parte/https://studylib.es/doc/7603846/ley-n\%C2\%BA-19.122---ministerio-de-desarrollo-social

${ }^{45}$ Ley 19122, "Afrodescendientes. Normas para favorecer su participación en las áreas educativa y laboral". Diario Oficial n. ${ }^{\circ} 28.795,9$ septiembre de 2013.

${ }^{46}$ Programa de Historia $2^{\underline{o}}$ año CB, reformulación 2006.

${ }^{47}$ Arturo Bentancur, Alex Borucki y Ana Frega, Estudios sobre la cultura afrorioplatense. Historia y presente (Montevideo: FHCE, 2004).

${ }^{48}$ Queimada, Xica Da Silva, El ocaso de los zulúes, Las cuatro plumas y Shaka Zulú.

${ }^{49}$ Manuel Fernández Ramírez, "Representaciones de las africanidades, las historias y culturas africanas en los currículos de Historia en Uruguay" (Ponencia, XVI Jornada Interescuelas / Departamento de Historia, Facultad de Humanidades, Universidad Nacional de Mar del Plata, 9, 10 y 11 de agosto 2017). 
En cuanto a los programas de Geografía, establecen para 2. ${ }^{\circ}$ año el trabajo sobre el espacio caribeño como la expresión de un espacio multicultural e intercultural. Mientras que para el tópico desplazados/refugiados se sugiere el estudio del caso colombiano ${ }^{50}$, sobre todo la zona del Chocó, ubicada en la costa del Pacífico colombiano, donde las poblaciones afro son las principales víctimas del conflicto armado, las mafias de narcotraficantes y las políticas extractivistas.

En el programa de $1 .^{\text {er }}$ año para ciclo básico no se menciona al continente africano como escenario inicial del desarrollo de la humanidad, cuando entre sus contenidos se sugiere trabajar el proceso de hominización. Cuando se señala el estudio de los aportes de las civilizaciones de Oriente y América, muchos docentes trabajan la civilización egipcia, cuyo escenario es el noreste de África; sin embargo, su carácter afro no se menciona en los contenidos, mientras que la bibliografía específica es nula ${ }^{51}$. Esto devela las inercias cristalizadas de un eurocentrismo epistemológico que ha sido rebatido por la intelectualidad africana hace muchos años:

El golpe decisivo al racismo de las teorías europeo-centristas vino de Cheikh Anta Diop, un historiador senegalense, cuando publicó en 1954 su tesis - rechazada por la Universidad Sorbonne de París- con el título Nations nègres et Culture, en la edición Présence Africaine de París. La publicación de este libro fue un verdadero terremoto en el campo de las ciencias humanas, porque sostenía que, además de ser el lugar de origen de la humanidad, los africanos fueron los autores de la más brillante civilización que la humanidad haya conocido, Egipto. Con esta tesis, se destruyó todo el edificio de mentiras que había sido construido sobre el africano desde el inicio de la esclavitud hasta la colonización del continente. El coloquio del Cairo de 1974, organizado por la Unesco sobre la población de Egipto antiguo, y el desciframiento de la escritura meroítica demostraron la veracidad de la tesis del historiador senegalense, y pusieron punto final al debate sobre si Egipto era parte de la civilización africana o no ${ }^{52}$.

Si hacemos el ejercicio comparativo con el programa de Geografía para el mismo curso, encontramos varios casos de estudio que se refieren

${ }^{50}$ Programa de Geografía 2.․año ciclo básico, reformulación 2006.

${ }^{51}$ Programa de Historia 1.er año ciclo básico, reformulación 2006.

52 Jaques Bertrand Mengue Moli, "El poscolonialismo en África. Un debate abierto”, en Genealogías críticas de la colonialidad en América Latina, África y Oriente, coord. Karina Bidaseca (Buenos Aires: Clascso-Idaes, 2016), 208. 
específicamente a África. Las temáticas sugeridas son: la desertificación, la deforestación y los usos del agua, en las que se establecen como estudios de caso: Madagascar, Sudán, Egipto, Etiopía, Congo, Nigeria y la zona del Sahel ${ }^{53}$. Si bien es cierto que estas temáticas actuales constituyen problemas públicos globales, no dejan de generar una suerte de afropesimismo, al reafirmar la idea de África como una zona del no-ser en términos fanonianos; un lugar donde todo lo malo sucede. Este contraste entre los programas oficiales de Historia y Geografía deja clara la ausencia de integralidad y de transdisciplinariedad que definen los planes de estudio en la educación secundaria uruguaya, un currículo aún muy anclado en visiones asignaturistas, que presenta el conocimiento en forma fragmentada y carente de enfoques interdisciplinarios ${ }^{54}$.

El programa de Historia para $3 .^{\text {er }}$ año de ciclo básico establece entre sus contenidos el análisis y la problematización de la expansión europea del siglo $\mathrm{XIX}^{55}$; en general, los docentes de Historia solemos trabajar la Conferencia de Berlín de 1885 y el reparto de África. La mirada pone el foco en los europeos, puesto que este tema se anuda con la segunda etapa de la revolución industrial y se conecta posteriormente con la Primera Guerra Mundial. En la bibliografía recomendada, de 216 libros, solo uno se refiere específicamente a la historia de África ${ }^{56}$, mientras que, de las 127 películas sugeridas, apenas dos se refieren a procesos africanos ${ }^{57}$.

Resulta interesante el programa de Historia para 3. de bachillerato, Micro experiencia 2011, cuya unidad VI se llama: "El mundo afroasiático: de la descolonización al dilema del desarrollo" ${ }^{n 8}$ con una carga horaria estimada de 28 horas; como se desprende del título, aborda solo problemas contemporáneos y la bibliografía recomendada es mínima. En todos los programas de la disciplina Historia de los bachilleratos se acentúa la invisibilización; en el primer año, uno

\footnotetext{
${ }^{53}$ Programa de Geografía 1.er año ciclo básico, reformulación 2006.

${ }^{54}$ Esto no significa que, más allá de los programas oficiales, no haya docentes que intenten construir objetos de estudio transdisciplinares con colegas y estudiantes. También es cierto que, en el lenguaje educativo oficial, las referencias a la multidisciplinariedad, la interdisciplinariedad y la transdisciplinariedad son cada vez más frecuentes en los discursos, aunque en el caso de secundaria esto no se refleja en los programas de estudio.

55 Programa de Historia 3.er año ciclo básico, reformulación 2006.

${ }^{56}$ Catherine Coquery-Vidrovitch y Henri Moniot, África negra de 1800 a nuestros días (Barcelona: Labor, 1976).

${ }^{57}$ La batalla de Argel de Gillo Pontecorvo y El señor de la guerra de Andrew Nicoll

${ }^{58}$ Programa de Historia 3.er año bachillerato, Microexperiencia 2011.
} 
de los contenidos establece el trabajo con "otras experiencias socialistas" ${ }^{\circ 9} \sin$ hacer ninguna mención al denominado socialismo africano. Mientras que, de 70 libros recomendados, no hay bibliografía específica sobre África, excepto algún capítulo aislado en las varias obras generales que se consignan.

En los programas de 2. ${ }^{\circ}$ año de bachillerato, opción social-humanística, el único contenido mencionado son los procesos abolicionistas ${ }^{60}$; sin embargo, tanto la bibliografía como la filmografía es la misma que se recomienda para $2 . \stackrel{0}{0}$ año de ciclo básico. Para el mismo año, pero en su opción artística, en la que se pone énfasis en la historia del arte, se incurre y se reafirma la misma omisión que en $1 .^{\text {er }}$ año de ciclo básico; se menciona el arte egipcio, pero fuera de su encuadre africano. La única referencia a África son los contenidos dedicados a la diáspora judía en el continente y sus manifestaciones artísticas; migraciones que se dieron durante los siglos medievales en Europa Occidental ${ }^{61}$. Si hacemos un contrapunto con el programa de Geografía para el mismo nivel, encontramos entre los contenidos, aspectos y problemáticas que, como ya mencionamos, forman parte de las agendas globales, pero que, al mismo tiempo, refuerzan un cierto afropesimismo: "África, megaciudades, descontrol urbano. ONG contra el SIDA en África"62.

En cuanto a los programas de $3 .{ }^{\circ}$ de bachillerato, en su opción economía y social-humanística, en el caso del primero, los contenidos son nulos, mientras que la filmografía y la bibliografía sugeridas son exactamente las mismas que para $3{ }^{\text {er }}$ año de ciclo básico ${ }^{63}$. En el segundo caso, en el contenido Hacia un nuevo orden político internacional, se hace mención a África en relación a lo que el programa denomina Nuevos y viejos conflictos ${ }^{64}$.

Los aspectos a los que nos referimos en este último apartado aluden a las manifestaciones estructural-formales del currículo; según De Alba, las prácticas de resistencia, en las que también estarían las demandas del campo político afrodescendiente, se dan en el ámbito procesual-práctico del currículo, en su devenir, en lo que podríamos llamar el flujo cotidiano de la vida escolar. Es allí donde se opera lo que Plá denomina discurso histórico escolar. Donde creemos que es posible deconstruir el enfoque epistemológico occidentalizante

${ }^{59}$ Programa de Historia 1.er año bachillerato, reformulación 2006.

${ }^{60}$ Programa de Historia 2. año bachillerato, opción social-humanístico, reformulación 2006.

${ }^{61}$ Programa de Historia del Arte 2.ํㅡㄹ Bachillerato, opción artística, reformulación 2006.

${ }^{62}$ Programa de Geografía 2. año bachillerato, opción social-humanística, reformulación 2006.

${ }^{63}$ Programa de Historia 3.er año bachillerato, opción economía, reformulación 2006.

${ }^{64}$ Programa de Historia 3.er año bachillerato, opción social-humanística, reformulación 2006. 
que coloniza el currículo y que ha contribuido a provocar, como sostiene Fernández Ramírez, el desconocimiento de las conexiones étnicas con el espacio afrosubsahariano de los colectivos afrolatinoamericanos. El papel que la Historia ha jugado en la construcción de los mitos nacionales ha dejado fuera las voces afro. Tanto en lo normativo como en lo áulico, toman carácter las luchas constantes, el antagonismo que alienta la democracia. Como sostiene Casimiro Lopes, siguiendo a Laclau, las cosas pueden ser de otra forma; lo que nos parece natural es la sedimentación de sucesivas prácticas hegemónicas, ancladas en contextos histórico-sociales, que devienen en prácticas curriculares hibridizadas; poder observar esto desde el análisis político del discurso, como herramienta teórica y lógica de intelección, nos permite establecer algunas conexiones entre currículo, políticas de reconocimiento y campo político afrodescendiente.

\section{Referencias bibliográficas}

\section{Fuentes primarias}

\section{Documentos oficiales}

Conferencia Mundial contra el Racismo, la Discriminación Racial, la Xenofobia y las formas conexas de Intolerancia. Edición del 31 de agosto al 8 de setiembre de 2001, Durban, Sudáfrica.

Hacia un Plan Nacional contra el Racismo y la Discriminación. Informe final. Ministerio de Educación y Cultura - MEC. Uruguay 2011.

Ley 19122. "Afrodescendientes. Normas para favorecer su participación en las áreas educativa y laboral". DiarioOficial, n. ${ }^{\circ} 28.795,9$ de septiembre de 2013.

Ley 18437. Ley General de Educación. Publicada D.O. 16 ene/009- № 27654.

Programa de Historia $1^{0}$ año de Ciclo Básico. Reformulación 2006. Ces - Anep.

Programa de Geografía $1^{0}$ año Ciclo Básico. Reformulación 2006. Ces - Anep.

Programa de Historia $2^{0}$ año Ciclo Básico. Reformulación 2006. Ces - Anep.

Programa de Historia $3^{0}$ año Ciclo Básico. Reformulación 2006. Ces - Anep.

Programa de Historia $1^{0}$ año de Bachillerato. Reformulación 2006. Ces - Anep.

Programa de Historia $2^{\mathbf{o}}$ Año de Bachillerato. Opción Social-humanístico. Reformulación 2006. Ces - Anep.

Programa de Historia del Arte $2^{0}$ año de Bachillerato. Opción Artística. Reformulación 2006. Ces - Anep.

Programa de Geografía $2^{\mathbf{o}}$ año de Bachillerato. Opción Social-humanística. Reformulación 2006. Ces - Anep.

Programa de Historia $3^{\text {o }}$ año de Bachillerato. Opción Economía. Reformulación 2006. Ces - Anep. 
Programa de Historia $3^{\mathbf{o}}$ año Bachillerato. Opción Social-Humanística. Reformulación 2006. Ces - Anep.

Programa de Historia $3^{\mathbf{o}}$ año Bachillerato Micro experiencia 2011. Ces - Anep.

\section{Fuentes secundarias}

Asencio Sánchez, Germán. Proyecto de Investigación de dispositivos rituales afrouruguayos y su eficacia terapéutica: la danza de los muertos pobres. Montevideo: Facultad de Psicología - Udelar, 2015.

Bajtin, Mijail. Estética de la creación verbal. México: Siglo XXI, 1995.

Bentancur, Arturo; Borucki, Alex y Frega, Ana. "Estudios sobre la cultura afrorioplatense”. Historia y presente. Montevideo: FHCE, 2004.

Bhabha, Homi. El lugar de la cultura. Buenos Aires: Editorial Manantial, 2002.

Borucki, Alex. "Entre el aporte a la identidad nacional y la reivindicación de las minorías. Apuntes sobre los afrodescendientes y la esclavitud en la historiografía uruguaya”.Revista Historia Unisinos 10, n. 3 (2006).

Borucki, Alex; Chagas, Karla y Stalla, Natalia. "Debates y problemas sobre los estudios recientes en torno a la esclavitud en el Río de la Plata (1750-1850)”. Ponencia. Segundas Jornadas de Historia Regional Comparada / Primeras Jornadas de Economía Regional Comparada, Porto Alegre, Pontificia Universidade Católica do Río Grande do Sul, octubre 2005.

Brena, Valentina y Brown, Gonzalo. Guía didáctica: educación y afrodescendencias. Montevideo: Mides-Inmujeres-Anep, 2016.

Casimiro Lopes, Alice. “Teorías pós-críticas, política e currículo”. Educacão,Sociedade \& Culturas, n. ${ }^{\circ} 39$ (2013).

Coquery-Vidrovitch, Catherine y Henri Moniat. África negra de 1800 a nuestros días. Barcelona: Labor, 1976.

Cristiano, Juan Carlos. "Raíces africanas en Uruguay: un estudio sobre la identidad afrouruguaya”. Monografía final de grado, Licenciatura en Sociología, Facultad de Ciencias Sociales - Udelar, 2008.

Da Costa Pereira, Maria Zuleide. "A centralidade da pluralidade cultural nos debates contemporaneos no campo do currículo”. Currículo sem FronteirasIX, n.o.2 (2009).

De Alba, Alicia. Currículum: crisis, mito y perspectiva. Madrid: Miño y Dávila editores, 1998.

Derrida, Jacques. De la Gramatología. Madrid: Siglo XXI Editores, 1967.

Fernández Ramírez, Martín. "Representaciones de las africanidades, las historias y culturas africanas en los currículos de Historia en Uruguay”. Ponencia, XVI Jornada Interescuelas / Departamento de Historia, Universidad de Mar del Plata, 2017.

Laclau, Ernest. y Mouffe, Chantal. Hegemonía y estrategia socialista. Buenos Aires: Fondo de Cultura Económica, 1985.

Laclau, Ernesto. La razón populista. Buenos Aires: Fondo de Cultura Económica, 2005. 
Una mirada desde el análisis político del discurso a las conexiones entre campo político afrodescendiente...

Federico José Alvez Cavanna - Gustavo Diego Faget Caballero

Lao Montes, Agustín. “Cartografías del campo político afrodescendiente en América Latina y el Caribe”. En Más allá del decenio de los pueblos afrodescendientes, editado por Rosa Campoalegre Septien y Karina Bidaseca. Buenos Aires: Clacso, 2017.

Mengue Moli, Jaques Bertrand. "El poscolonialismo en África. Un debate abierto”. En Genealogías críticas de la colonialidad en América Latina, África y Oriente, coordinado por Karina Bidaseca. Buenos Aires: Clacso-Idaes, 2016.

Olaza, Mónica. "La cultura afrouruguaya una expresión del multiculturalismo emergente de la relación global-local”. Tesis de Maestría en Sociología, Facultad de Ciencias Sociales, Udelar, 2008.

Omar, Sidi Mohamed. Los estudios poscoloniales: una introducción crítica. Castellón: Publicaciones de la Universidad Jaume I, 2007.

Plá, Sebastián. "Evaluación de un profesor de Historia: un estudio de caso”. Ponencia, XI Congreso Nacional de Investigación Educativa / 5. Educación y Conocimientos Disciplinares, 2011.

Romero Gorski, Sonia. “Entrevista a Romero J. Rodríguez”. Revista de Antropología. (FHCE) (2001).

Rufer, Mario. "Nación y condición poscolonial. Sobre memoria y exclusión en los usos del pasado”. En Genealogías críticas de la colonialidad en América Latina, África y Oriente, coordinado por Karina Bidaseca. Buenos Aires: Clacso-Idaes, 2016.

Said, Edward. Orientalismo. Madrid: Ediciones Libertarias, 1990.

Sédar Senghor, Léopold. "El espíritu de la civilización o las leyes de la cultura africana negra”. En El nacionalismo africano en el siglo XX. Hans Kohn y Wallace Sokolsky. Traducción de Cristina Souverbielle. Buenos Aires: Paidós, 1968.

Spivak, Gayatri. "Estudios de la subalternidad. Deconstruyendo la historiografía”. En Estudios poscoloniales: ensayos fundamentales, compilado por Sandro Mezzadra. Madrid: Ediciones Traficantes de Sueños, 2008.

Sucro Somma, Lucía,coord. Población afrodescendiente y desigualdades étnico-raciales en Uruguay. Montevideo: PNUD, 2008.

Vera, Lil Natalia. "Discriminación racial e identidad: la experiencia de las generaciones recientes de afrodescendientes en Uruguay”. Monografía final de grado, Licenciatura en Sociología, Facultad de Ciencias Sociales, Udelar, 2011.

Walsh, Catherine. "Fanon y la pedagogía decolonial". Revista NuevAmérica, 122 (junio, 2009): 60-63.

Walsh, Catherine. "Interculturalidad, plurinacionalidad y decolonialidad: las insurgencias político-epistémicas de refundar el Estado”. Tabula Rasa, n. 9 (julio-diciembre, 2008): 131-152.

Walsh, Catherine. "Interculturalidad, conocimientos y decolonialidad”. Signo y Pensamiento XXIV, n. ${ }^{\circ} 46$ (enero-junio 2005): 39-50.

Yedaide, Marta. "Fanon, Freire y las posibilidades concretas de una pedagogía descolonial: entrevista a Inés Fernández Mouján”. Revista Entramados (2014), http://fh.mdp.edu.ar/revistas/index.php/entramados

Young, Robert. ¿¿Qué es la crítica poscolonial?” (2006), http//robertjyoung.com/ crítica poscolonial.pdf 